\title{
TEMPERATURA NO ARMAZENAMENTO DE PITANGA
}

\author{
Enayde de Almeida Mélo1*; Vera Lúcia Arroxelas Galvão de Lima1; Poliana Pinheiro do \\ Nascimento ${ }^{2}$ \\ ${ }^{1}$ Depto. de Ciências Domésticas, UFRPE - Rua Dom Manoel de Medeiros s/n, Dois Irmãos, CEP: 52171-900 - \\ Recife, PE. \\ ${ }^{2}$ Graduando do Depto. de Ciências Domésticas, UFRPE. \\ *Autor correspondente<eamelo@elogica.com.br>
}

RESUMO: A pitanga (Eugenia uniflora L) é um fruto tropical de elevada perecibilidade que apresenta problemas durante o seu armazenamento e comercialização afetando a qualidade do fruto "in natura". Com objetivo de investigar a influência da temperatura no armazenamento de pitangas em três estádios de maturação, frutos verdes, semi-maduros e maduros foram armazenados durante 30 dias sob refrigeração $\left(8^{\circ} \mathrm{C} \pm 1 /\right.$ U.R.90-95\%) e 90 dias sob congelamento $\left(-18^{\circ} \mathrm{C}\right)$. Em intervalos de $05,10,20,30,60$, e 90 dias, foram determinados o peso médio, o pH, o teor de sólidos solúveis totais, a acidez total titulável e o teor de vitamina $\mathrm{C}$ total. Os frutos, independentemente do estádio de maturação e do tratamento aplicado, apresentaram perda de peso. A refrigeração manteve, praticamente, inalterada a aparência externa dos frutos maduros e semi-maduros até 10 dias de armazenamento e, no caso de pitangas verdes até 20 dias sem, contudo, permitir o seu amadurecimento. As características intrínsecas dos frutos (SST, pH, ATT e vitamina C) foram alteradas pelos tratamentos usados, à exceção do teor de vitamina $C$ nos frutos congelados, que ao final do período de armazenamento foi semelhante ao teor inicial. Pitangas maduras e semi-maduras armazenadas sob refrigeração apresentaram possibilidade de conservação por um período de até 05 dias. 0 congelamento de pitangas maduras e semi-maduras, por alterar intensamente as características físicas dos frutos, pode ser apenas indicado para frutos destinados à industrialização.

Palavras-chave: Eugenia uniflora, armazenamento, conservação

\section{TEMPERATURE AND THE STORAGE OF SURINAM CHERRIES}

\begin{abstract}
Surinam cherry is a tropical fruit of high perishability, a factor which implies in storage and commercialisation problems and effects the quality of the fruit "in natura". The purpose of this research was to verify the influence of temperature on the storage of surinam cherries. Green, half-mature and mature fruits were stored during 30 days under refrigeration ( $8^{\circ} \mathrm{C} \pm 1 /$ U.R. $\left.90-95 \%\right)$ and during 90 days under freezing temperatures $\left(-18^{\circ} \mathrm{C}\right)$. Average weight, $\mathrm{pH}$, total acidity and soluble solids and total vitamin $\mathrm{C}$ contents of the fruits were measured at intervals of $05,10,20,30,60$ and 90 days. A decrease in weight was observed for all fruits, regardless of maturation stage and treatment. Refrigeration preserved the innate external appearance of half-mature and mature fruits up to 10 days of storage. Refrigeration preserved innate external appearance of green surinam cherries for 20 days but prevented the maturation process. The intrinsic characteristics of the fruits ( $\mathrm{pH}$, soluble solids, total acidity and total vitamin $\mathrm{C}$ ) were altered by the treatments, except for vitamin $\mathrm{C}$ content in the frozen fruits which at the end of the storage period was similar to the initial rate. Mature and halfmature surinam cherries stored under refrigeration showed the possibility of preservation up to 05 days. Because of the intense alteration on physical characteristics caused by freezing, the mature and half-mature surinam cherries can only be just used for further processing.

Key words: Eugenia uniflora, storage, preservation
\end{abstract}

\section{INTRODUÇÃO}

A pitanga (Eugenia uniflora $\mathrm{L}$ ) é um fruto tropical, pertencente à família das Mirtáceas, nativo das regiões Sul e Sudeste do Brasil e que tem se adaptado favoravelmente às condições climáticas e edáficas da Região Nordeste. Esse fruto, bastante apreciado devido ao seu sabor agradável e refrescante, é uma baga de aproximadamente $30 \mathrm{~mm}$ de diâmetro, com 8 a 10 sucos longitudinais, achatada nas extremidades (Gomes, 1975). Durante o processo de maturação a cor do fruto evolui de verde a alaranjado atingindo a coloração vermelha intensa ou roxa ao apresentar-se completamente maduro. Neste estádio, os frutos são vulneráveis à deterioração devido a sua fragilidade, dificultando seu transporte e comercialização.

Em Pernambuco, a maior parte da produção do fruto provém de pequenos pomares domésticos, localizados no Grande Recife e em outros municípios da Zona da Mata e Agreste Meridional. Entretanto, vários pequenos produtores têm demonstrado interesse em explorar comercialmente a pitangueira face ao crescente consumo do fruto, principalmente na forma de polpa congelada. Diante disso, a Empresa Pernambucana de Pesquisa Agropecuária -IPA através do banco de germoplasma, instalado na Estação Experimental de Itambé - PB, tem selecionado plantas com boas características de crescimento e produção. As seleções estudadas apresentaram uma produtividade média de 11 
a $12,7 \mathrm{~kg}$ de frutos por ano com dois períodos de colheita. O primeiro ocorre nos meses de abril a maio e o segundo de agosto a outubro com $21,9 \%$ e $60,8 \%$ do total da produção, respectivamente (Bezerra et al., 1997).

As características físicas e químicas da pitanga foram estudadas por diversos pesquisadores bem como os aspectos agronômicos referentes à produtividade de seleções e algumas características de qualidade relacionadas a cor, peso médio, percentual de polpa e caroço do fruto (Gomes, 1975; Bezerra et al., 1997; Lederman et al., 1992). Entretanto, referências bibliográficas sobre a fisiologia pós-colheita deste fruto são escassas. Desta forma, este trabalho teve como objetivo realizar um estudo preliminar sobre a influência da temperatura de armazenamento de pitangas, em diferentes estádios de maturação, submetidas à refrigeração e ao congelamento.

\section{MATERIAL E MÉTODOS}

As pitangas, fisiologicamente desenvolvidas, provenientes de diferentes plantas do pomar de um produtor, localizado em Aldeia - PE, foram colhidas no período da manhã em três estádios de maturação. Para classificação dos frutos quanto ao estádio de maturação foi considerado o grau de cor da casca, a saber: frutos verdes, aqueles que apresentavam mais de $75 \%$ da casca com coloração verde; frutos semi-maduros, aqueles que apresentavam mais de $75 \%$ da casca com coloração alaranjada e frutos maduros, aqueles que apresentavam $100 \%$ da casca com coloração vermelha. Os frutos colhidos foram imediatamente transportados ao Laboratório de Análises Físico - Químicas e Sensorial de Alimentos - DCD / UFRPE, selecionados para eliminar aqueles que apresentavam ferimento mecânico e ataque fúngico, lavados em água clorada e colocados sobre uma superfície, expostos a uma corrente de ar forçada, para secarem. De acordo com o estádio de maturação, os frutos foram agrupados em três lotes, contendo cada um deles 60 porções com aproximadamente $200 \mathrm{~g}$ de frutos. As porções foram acondicionadas em sacos de polietileno de 14 micras e lacrados em máquina de selagem à quente. Os sacos foram dispostos em camada única e armazenados sob refrigeração $\left(8^{\circ} \mathrm{C} \pm 1 /\right.$ U.R. $\left.90-95 \%\right)$ e sob congelamento ($18^{\circ} \mathrm{C}$ ) por um período de 30 e 90 dias, respectivamente. Amostras de cada lote, constituídas por cinco porções de frutos, foram retiradas ao acaso e submetidas às análises física, físico - química e química no tempo zero de armazenamento, utilizada para comparação com os tratamentos, e a intervalos de 5, 10, 20, 30, 60, e 90 dias. Ao término de cada período de armazenamento, os frutos foram transferidos para condições ambientais, as embalagens foram retiradas e imediatamente avaliados quanto à perda de peso em porcentagem, por pesagem direta, considerandose o peso inicial de cada unidade. Em seguida, os frutos de cada lote foram triturados separadamente, para extração do suco, o qual após a homogeneização foi submetido às seguintes determinações: sólidos solúveis totais (SST), pH e acidez total titulável (ATT) de acordo com a metodologia da AOAC (1990) e vitamina C total pelo método espectrofotométrico utilizando 2,4 - dinitrofenilhidrazina (Strohecker \& Henning, 1965). Os dados obtidos foram submetidos à análise de variância e teste de Tukey a 5\% para comparação dos tratamentos, (SAS Institute, 1992).

\section{RESULTADOS E DISCUSSÃO}

\section{Pitangas armazenadas sob refrigeração $\left(8^{\circ} \mathrm{C} \pm 1 /\right.$ U.R. 90-95\%)}

A refrigeração permitiu prolongar a vida útil dos frutos maduros e semi-maduros até 10 dias e no caso de pitangas verdes até 20 dias. O fator decisivo para determinar esse período foi o surgimento de frutos deteriorados, ou seja, frutos com aparência externa e odor desagradáveis. Os frutos nos três estádios de maturação apresentaram as mesmas características de deterioração, entretanto o percentual de frutos deteriorados foi diferenciado. Nesses períodos a taxa de deterioração foi de $18 \%$ para as pitangas maduras, $10,7 \%$ para as pitangas semi-maduras e de $36,7 \%$ para os frutos verdes. No período subsequente esta taxa foi superior a $50 \%$, o que impôs a interrupção do experimento.

Os frutos apresentaram perda de peso ao longo do período de armazenamento, independentemente do estádio de maturação (TABELA 1). As pitangas maduras e verdes apresentaram maiores perdas de peso do que as semi-maduras, atingindo aos 10 dias de armazenamento uma redução no peso de $11,91 \%, 10,00 \%$ e $2,13 \%$, respectivamente. Segundo Hardenburg et al. (1988), a qualidade de um fruto é depreciada quando este perde de 3 a $6 \%$ de seu peso.

As pitangas verdes tornaram-se amareladas a partir do $5^{\circ}$ dia de armazenamento, porém até o fim do experimento a coloração vermelha estava ausente, tornandose portanto, impróprias à comercialização quer seja para consumo in natura quer seja para industrialização. A inexistência da coloração vermelha nesses frutos se deve, possivelmente, à ausência do licopeno, principal pigmento da pitanga madura (Cavalcante, 1991), cuja síntese ocorre na faixa de temperatura de $10^{\circ}$ a $37^{\circ} \mathrm{C}$ (Barret Reina et al., 1994). Desse modo, pode-se inferir que a temperatura de armazenamento a $8^{\circ} \mathrm{C}$ não favorece o amadurecimento das pitangas verdes.

Geralmente, durante o amadurecimento de frutos ocorre o aumento progressivo do teor de SST em decorrência da transformação dos polissacarídeos insolúveis em açúcares solúveis, e diminuição da ATT. Sendo assim, a relação SST/ATT tende a aumentar. O teor inicial dos SST apresentado pelas pitangas maduras $(4,0 \%)$, semi-maduras $(3,6 \%)$ e verdes $(2,0 \%)$ foi muito baixo quando comparado ao valor de $9,4 \%$ encontrado por Guimarães et al.(1982) para o fruto maduro. Provavelmente, este baixo teor se deve a fatores 
TABELA 1 - Porcentagem média de perda de peso em pitangas em diferentes estádios de maturação armazenadas sob refrigeração $\left(8^{\circ} \mathrm{C} \pm 1 /\right.$ U.R. $\left.90-95 \%\right)$ e sob congelamento $\left(-18^{\circ} \mathrm{C}\right)$ e embaladas em sacos de polietileno.

\begin{tabular}{llrrrrrc}
\hline \multirow{2}{*}{$\begin{array}{l}\text { Condições de } \\
\text { armazenamento }\end{array}$} & $\begin{array}{l}\text { Estádio de } \\
\text { maturação }\end{array}$ & \multicolumn{7}{c}{ Tempo de armazenamento (dias) } \\
\cline { 3 - 7 } & & 5 & 10 & 20 & 30 & 60 & 90 \\
\hline \multirow{4}{*}{ Refrigeração } & Madura & 3,22 & 11,91 & - & - & - & - \\
& Semi-madura & 1,52 & 2,13 & - & - & - & - \\
& Verde & 6,00 & 10,00 & 18,80 & - & - & - \\
\hline \multirow{3}{*}{ Congelamento } & Madura & 2,73 & 8,43 & 9,92 & 14,89 & 15,14 & 15,14 \\
& Semi-madura & 0,00 & 0,91 & 2,45 & 4,57 & 4,87 & 5,48 \\
& Verde & 0,00 & 0,40 & 2,80 & 3,20 & 6,80 & 11,60 \\
\hline
\end{tabular}

climáticos uma vez que as pitangas usadas neste estudo foram colhidas em época de chuva. O teor de SST das pitangas maduras e semi-maduras (TABELA 2) diminuiu significativamente $(p>5 \%)$ ao longo do período de armazenamento, enquanto que nos frutos verdes esta variável permaneceu constante, apresentando um declínio aos 20 dias de estocagem (dados não apresentados).

Durante 0 armazenamento dos frutos, o pH apresentou, independentemente do estádio de maturação, um leve declínio, entretanto esta variação foi estatisticamente significativa $(p>5 \%)$ (TABELA 3). Na pitanga madura ocorreu um aumento, estatisticamente significativo, da ATT aos 10 dias de armazenamento. $O$ aumento da acidez titulável decorreu, possivelmente, da fermentação produzida pela flora microbiana evidenciando ter havido deterioração dos frutos e, consequentemente, perda do seu valor comercial. No que se refere aos frutos semimaduros não houve alteração da acidez enquanto que nos frutos verdes a acidez foi reduzida de forma significativa ao longo do período de armazenamento (TABELA 4).

$O$ teor inicial de vitamina $C$ total das pitangas variou em função do estádio de maturação. Pitangas verdes possuem um maior teor de vitamina $C$ do que as semi-maduras e maduras (TABELA 5). Os frutos maduros apresentaram teor desta vitamina mais elevado do que 0 relatado por Guimarães et al. (1982) e Cavalcante (1991) cujos valores foram $29,4 \mathrm{mg} \%$ e $16 \mathrm{mg} \%$, respectivamente. A composição química de frutos e hortaliças pode ser afetada por diversos fatores, a exemplo do grau de maturação, condições climáticas, edáficas e cultivares analisados, entre outros (Harris, 1977). Assim, a influência desses fatores poderia explicar a discrepância encontrada entre os valores de vitamina $C$ da pitanga relatados pelos autores acima citados e o encontrado neste estudo. No início do período de estocagem, os frutos, independente do estádio de maturação, apresentaram um aumento significativo no teor de vitamina C. Esse aumento foi maior nas pitangas maduras (38\%) do que nas semi-maduras $(29 \%)$ e verdes $(17 \%)$. Nas pitangas maduras e semi-maduras esse teor continuou a aumentar progressivamente até o final do período de armazenamento, no entanto, essa variação não foi
TABELA 2 - Valores médios do teor de sólidos solúveis totais (SST) de pitangas em diferentes estádios de maturação armazenadas sob refrigeração $\left(8^{\circ} \mathrm{C} \pm 1 /\right.$ U.R. $\left.90-95 \%\right)$ e embaladas em sacos de polietileno.

\begin{tabular}{lccc}
\hline $\begin{array}{l}\text { Estádio de } \\
\text { maturação }\end{array}$ & \multicolumn{3}{c}{ Tempo de armazenamento ( dias) } \\
\cline { 2 - 4 } & 0 & 5 & 10 \\
\hline & $-0-1,0 \mathrm{a}$ & $3,0 \mathrm{~b}$ & $2,0 \mathrm{c}$ \\
Maduro & $4,0 \mathrm{a}$ & $1,2 \mathrm{c}$ \\
Semi-maduro & $3,6 \mathrm{a}$ & $2,0 \mathrm{~b}$ & $2,0 \mathrm{a}$ \\
\hline
\end{tabular}

Médias com as mesmas letras na linha não diferem estatisticamente pelo teste de Tukey a $5 \%$.

TABELA 3 - Valores médios de pH de pitangas em diferentes estádios de maturação armazenadas sob refrigeração $\left(8^{\circ} \mathrm{C} \pm 1 /\right.$ U.R. $\left.90-95 \%\right)$ e embaladas em sacos de polietileno.

\begin{tabular}{lccc}
\hline Estádio de & \multicolumn{3}{c}{ Tempo de armazenamento ( dias) } \\
\cline { 2 - 4 } maturação & 0 & 5 & 10 \\
\hline Maduro & $2,8 \mathrm{a}$ & $2,7 \mathrm{~b}$ & $2,7 \mathrm{~b}$ \\
Semi-maduro & $2,7 \mathrm{a}$ & $2,6 \mathrm{~b}$ & $2,6 \mathrm{~b}$ \\
Verde & $2,9 \mathrm{a}$ & $2,8 \mathrm{~b}$ & $2,8 \mathrm{~b}$ \\
\hline
\end{tabular}

Médias com as mesmas letras na linha não diferem estatisticamente pelo teste de Tukey a $5 \%$.

TABELA 4 - Valores médios de acidez total titulável (ATT) de pitangas em diferentes estádios de maturação armazenadas sob refrigeração $\left(8^{\circ} \mathrm{C} \pm 1 /\right.$ U.R. $90-95 \%)$ e embaladas em sacos de polietileno.

\begin{tabular}{llcc}
\hline $\begin{array}{l}\text { Estádio de } \\
\text { maturação }\end{array}$ & \multicolumn{4}{c}{ Tempo de armazenamento ( dias) } \\
\cline { 2 - 4 } & 0 & 5 & 10 \\
\hline & g de ácido cítrico & $100 \mathrm{~g}^{-1}$ de suco \\
Maduro & $1,68 \mathrm{a}$ & $1,73 \mathrm{a}$ & $2,27 \mathrm{~b}$ \\
Semi-maduro & $2,33 \mathrm{a}$ & $2,17 \mathrm{a}$ & $2,12 \mathrm{a}$ \\
Verde & $2,24 \mathrm{a}$ & $2,12 \mathrm{~b}$ & $2,01 \mathrm{c}$ \\
\hline
\end{tabular}

Médias com as mesmas letras na linha não diferem estatisticamente pelo teste de Tukey a $5 \%$. 
TABELA 5 - Valores médios de vitamina $C$ total de pitangas em diferentes estádios de maturação armazenadas sob refrigeração $\left(8^{\circ} \mathrm{C} \pm 1 /\right.$ U.R. $\left.90-95 \%\right)$ e embaladas em sacos de polietileno.

\begin{tabular}{lccc}
\hline $\begin{array}{l}\text { Estádio de } \\
\text { maturação }\end{array}$ & \multicolumn{4}{c}{ Tempo de armazenamento ( dias) } \\
\cline { 2 - 4 } & \multicolumn{2}{c}{5} & 10 \\
\hline & $-12,9 \mathrm{a}$ & $59,4 \mathrm{~b}$ & $63,8 \mathrm{~b}$ \\
Maduro & $36,1 \mathrm{a}$ & $46,7 \mathrm{~b}$ & $48,1 \mathrm{~b}$ \\
Semi-maduro & $54,4 \mathrm{a}$ & $63,9 \mathrm{~b}$ & $60,3 \mathrm{ab}$ \\
\hline
\end{tabular}

Médias com as mesmas letras na linha não diferem estatisticamente pelo teste de Tukey a $5 \%$.

significativa $(p<5 \%)$. No que se refere às pitangas verdes houve uma redução no teor de vitamina $\mathrm{C}$ aos 10 dias de armazenamento porém, estatisticamente, o valor encontrado foi semelhante ao inicial. Alterações no teor de vitamina $C$, também, foram observadas por Kanesiro et al. (1996) em goiabas submetidas à refrigeração $\left(9^{\circ} \mathrm{C}\right)$ em diferentes sistemas de embalagens. $O$ aumento no teor desse constituinte pode ser explicado como um efeito de compensação pela perda de água durante 0 armazenamento, evidenciada pela redução do peso e diâmetro dos frutos, com conseqüente concentração do suco (Carvalho e Manica, 1994). Neste estudo, a redução de peso apresentada pelas pitangas poderia justificar a alteração no teor de vitamina $\mathrm{C}$ observada.

\section{Pitangas armazenadas sob congelamento $\left(-18^{\circ} \mathrm{C}\right)$}

O congelamento não alterou a coloração dos frutos exceto os colhidos verdes cuja pigmentação característica foi modificada para verde oliva. A textura dos frutos, observada através da pressão dos dedos, tornouse amolecida, principalmente a dos frutos maduros. Os frutos apresentaram, também, perda de peso, independente do estádio de maturação (TABELA 1). Essas modificações se devem à destruição da integridade celular em função da formação de cristais de gelo que contribuem para perda da rigidez normal bem como para perda de líquido intra-celular (Sigrist, 1988). No emprego do congelamento lento, técnica usada neste estudo, essas alterações são mais pronunciadas em virtude do tamanho dos cristais de gelo formados.

Nos três estádios de maturação, o pH apresentou uma variação ao longo do período de armazenamento, atingindo os mais baixos valores aos 90 dias de estocagem, os quais foram estatisticamente significativos quando comparados aos valores iniciais. Os teores de SST dos frutos, independentemente do estádio de maturação, apresentaram uma variação estatisticamente significativa ao longo do período de armazenamento. O teor de SST das pitangas maduras manteve constante até $010^{\circ}$ dia de armazenamento para em seguida apresentar uma diminuição. Esta variável, nas semi-maduras apresentou uma tendên- cia de decréscimo a partir do $5^{\circ}$ dia de armazenamento. Nos frutos verdes, os teores de SST aumentaram a partir do $5^{\circ}$ dia e, aos 20 dias de armazenamento apresentaram uma redução, no entanto, ao final do experimento atingiram um valor levemente superior ao inicial (TABELAS 6 e 7). Segundo Barret Reina et al. (1993), a redução do SST é explicada pelo início das reações catabólicas que conduzem à senescência. Diante dos resultados obtidos neste trabalho, pode-se inferir que o congelamento não interrompe totalmente as reações catabólicas da senescência nos frutos maduros e semi-maduros. Isto, possivelmente, decorre do fato de que na temperatura de congelamento $\left(-18^{\circ} \mathrm{C}\right)$ uma proporção de água congelável ainda se encontra no estado líquido (2-15\%) a qual possui propriedades solvente e reativa, permitindo a continuidade de algumas reações metabólicas (Cheftel et al., 1983).

A ATT dos frutos nos três estádios de maturação apresentou variação ao longo do período de estocagem (TABELA 8). Comparando os valores encontrados no final do experimento com os valores iniciais observa-se que, apenas para as pitangas maduras, esta variação não foi estatisticamente significativa. A diminuição da ATT em frutos é esperada durante o processo de amadurecimento em decorrência do catabolismo dos ácidos presentes, o que realça o seu sabor doce. A variação nos valores de ATT evidenciada neste estudo poderia ser um indicativo de que as reações catabólicas não foram totalmente interrompidas.

TABELA 6 - Valores médios de pH de pitangas em 3 estádios de maturação armazenadas sob congelamento $\left(-18^{\circ} \mathrm{C}\right)$ e embaladas em sacos de polietileno.

\begin{tabular}{|c|c|c|c|c|c|c|}
\hline \multirow{2}{*}{$\begin{array}{l}\text { Estádio } \\
\text { de } \\
\text { maturação }\end{array}$} & \multicolumn{6}{|c|}{ Tempo de armazenamento ( dias) } \\
\hline & 0 & 5 & 10 & 30 & 60 & 90 \\
\hline Maduro & $2,8 \mathrm{a}$ & $2,9 \mathrm{~b}$ & 3,0 c $2,9 b$ & $2,7 d$ & $2,8 \mathrm{a}$ & $2,4 \mathrm{e}$ \\
\hline $\begin{array}{l}\text { Semi- } \\
\text { maduro }\end{array}$ & $2,7 \mathrm{a}$ & $2,8 \mathrm{~b}$ & 2,8 b 2,8 b & $2,6 \mathrm{c}$ & $2,9 \mathrm{~d}$ & $2,2 \mathrm{e}$ \\
\hline Verde & $2,9 \mathrm{a}$ & $3,0 \mathrm{~b}$ & 2,9 a 2,9 a & $2,7 \mathrm{c}$ & $2,9 \mathrm{a}$ & $2,6 \mathrm{~d}$ \\
\hline
\end{tabular}

Médias com as mesmas letras na linha não diferem estatisticamente pelo teste de Tukey a $5 \%$.

TABELA 7 - Valores médios do teor de sólidos solúveis totais (SST) de pitangas em diferentes estádios de maturação armazenadas sob congelamento $\left(-18^{\circ} \mathrm{C}\right)$ e embaladas em sacos de polietileno.

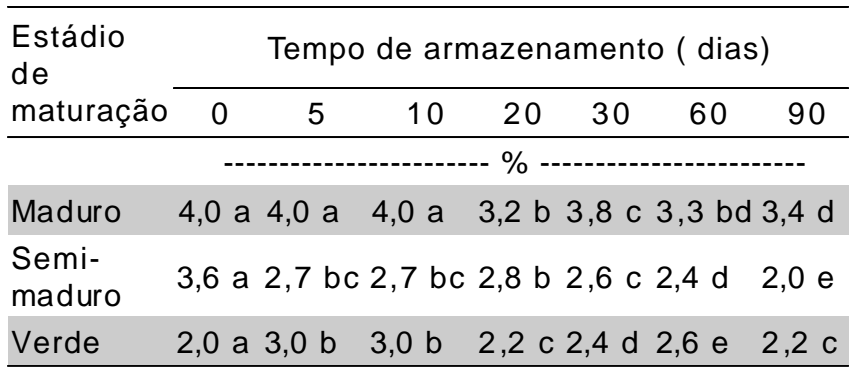

Médias com as mesmas letras na linha não diferem estatisticamente pelo teste de Tukey a $5 \%$. 
O teor de vitamina $C$ total das pitangas nos três estádios de maturação apresentou um aumento nos primeiros 5 dias de estocagem e um decréscimo nos períodos subsequentes (TABELA 9). Silva (1994) também detectou aumento no teor de vitamina $\mathrm{C}$ em acerolas armazenadas sob congelamento sem contudo justificar a ocorrência do fato. Hopkins (1967) observou que frutas submetidas a injúrias, após alguns dias, sofrem uma elevação no teor dessa vitamina que pode ser explicado como um mecanismo de defesa dos frutos. Por outro lado, o decréscimo do conteúdo de vitamina $C$ durante os períodos subsequentes de armazenamento se deve, possivelmente, às reações enzimáticas e não enzimáticas que continuam a ocorrer, levando à destruição desse nutriente (Nagy, 1980). Entretanto, os valores de vitamina $C$ determinados ao final do experimento não apresentaram diferença estatisticamente significativa quando comparados com os valores iniciais, evidenciando que a temperatura, nas condições experimentais, não exerceu influência sobre o teor desse constituinte. Ao final do período de estocagem, a retenção desta vitamina foi na ordem de $90 \%, 72 \%$ e $98 \%$ para as pitangas maduras, semi-maduras e verdes, respectivamente.

\section{CONCLUSÕES}

- O armazenamento sob refrigeração permite manter a qualidade das pitangas maduras e semi-maduras por período de até cinco dias, onde a perda de peso e as alterações das características físicas, químicas e físicoquímicas não são tão intensas. No entanto, outros estudos devem ser desenvolvidos com vistas a minimizar, ainda mais, essas alterações e, consequentemente, ampliar o seu tempo de armazenamento.
- A temperatura de refrigeração não favorece 0 amadurecimento das pitangas verdes.

- O uso do congelamento na conservação de pitangas altera as características físico-químicas dos frutos, com exceção do teor de vitamina $\mathrm{C}$ que ao final do período de armazenamento é semelhante ao teor inicial.

- As alterações físicas promovidas pelo congelamento são bastante intensas e, dessa forma, esse tratamento deve ser indicado para os frutos maduros e semi-maduros destinados à industrialização, por apresentarem aparência indesejável para frutos destinados ao consumo in natura.

\section{AGRADECIMENTOS}

Ao Prof. Dr. Gabriel Rivas, do Departamento de Física e Matemática - UFRPE, pela orientação na realização da análise estatística e ao PIBIC-CNPq/UFRPE pelo apoio financeiro.

\section{REFERÊNCIAS BIBLIOGRÁFICAS}

ASSOCIATION OF OFFICIAL ANALYTICAL CHEMISTS. Official methods of analysis of the Association of Official Analytical Chemists. 15.ed. Arlington: AOAC, 1990.

BARRET REINA, L. del C.; CHITARRA, M.I.F.; CHITARRA, A.B. Choque a frio e atmosfera modificada no aumento da vida pós-colheita de tomates: 2. Coloração e textura. Ciência e Tecnologia de Alimentos, v.14, p.14-26, 1994.

BARRET REINA, L. del C.; CHITARRA, M.I.F.; CHITARRA, A.B. Choque a frio e atmosfera modificada no aumento da vida pós-colheita de tomate: I. Avaliação da qualidade. Ciência e Tecnologia de Alimentos, v.13, p.168-183, 1993

TABELA 8 - Valores médios da acidez total titulável (ATT) de pitangas em diferentes estádios de maturação armazenadas sob congelamento $\left(-18^{\circ} \mathrm{C}\right)$ e embaladas em sacos de polietileno.

\begin{tabular}{lllllllc}
\hline \multirow{2}{*}{$\begin{array}{l}\text { Estádio de } \\
\text { maturação }\end{array}$} & \multicolumn{7}{c}{ Tempo de armazenamento (dias) } \\
\cline { 2 - 7 } & 0 & 5 & 10 & 20 & 30 & 60 & 90 \\
\hline \multirow{2}{*}{ Maduro } & $1,68 \mathrm{ac}$ & $1,87 \mathrm{~b}$ & $1,66 \mathrm{a}$ & $1,70 \mathrm{ac}$ & $1,77 \mathrm{bc}$ & $1,75 \mathrm{ac}$ & $1,75 \mathrm{ac}$ \\
Semi-maduro & $2,33 \mathrm{a}$ & $2,15 \mathrm{abc}$ & $1,98 \mathrm{c}$ & $2,05 \mathrm{bc}$ & $2,15 \mathrm{abc}$ & $2,24 \mathrm{ab}$ & $2,03 \mathrm{bc}$ \\
Verde & $2,24 \mathrm{a}$ & $2,22 \mathrm{a}$ & $2,08 \mathrm{~b}$ & $1,87 \mathrm{c}$ & $1,96 \mathrm{c}$ & $2,10 \mathrm{~b}$ & $1,96 \mathrm{c}$ \\
\hline
\end{tabular}

Médias com as mesmas letras na linha não diferem estatisticamente pelo teste de Tukey a $5 \%$.

TABELA 9 - Valores médios de vitamina $C$ total de pitangas em diferentes estádios de maturação armazenadas sob congelamento $\left(-18^{\circ} \mathrm{C}\right)$ e embaladas em sacos de polietileno.

\begin{tabular}{|c|c|c|c|c|c|c|c|}
\hline \multirow{2}{*}{$\begin{array}{l}\text { Estádio de } \\
\text { maturação }\end{array}$} & \multicolumn{7}{|c|}{ Tempo de armazenamento ( dias) } \\
\hline & 0 & 5 & 10 & 20 & 30 & 60 & 90 \\
\hline & \multicolumn{7}{|c|}{ - } \\
\hline Maduro & $42,9 a b$ & 47,4 a & 46,3 a & 47,7 a & $40,4 a b$ & $35,0 \mathrm{~b}$ & $38,6 \mathrm{ab}$ \\
\hline Semi-maduro & 36,1 ac & $50,0 \mathrm{~b}$ & 40,4 a & 40,6 a & 40,8 a & $31,2 \mathrm{c}$ & $33,1 \mathrm{c}$ \\
\hline Verde & $54,4 \mathrm{a}$ & $78,1 \mathrm{~b}$ & $77,2 \mathrm{~b}$ & $62,1 \mathrm{c}$ & $66,1 d$ & $51,0 \mathrm{e}$ & $52,9 \mathrm{ae}$ \\
\hline
\end{tabular}

Médias com as mesmas letras na linha não diferem estatisticamente pelo teste de Tukey a $5 \%$. 
BEZERRA, J.E.F.; PREITAS, E.V. de; PEDROSA, A.C.; LEDERMAN, I.E.; DANTAS, A.P. Performance of Surinam Cherry (Eugenia uniflora L.) in Pernambuco, Brazil: II. productive period 1989 - 1995. Acta Horticulturae, n.452, p.137-142, 1997.

CARVALHO, R.I.N.; MANICA, I. Influência de estádios de maturação e condições de armazenamento na conservação de acerola (Malpighia glabra L.). Pesquisa Agropecuária Brasileira, v.29, p.681-688, 1994.

CAVALCANTE, M.L. Composição de carotenóides e valor de vitamina A na pitanga (Eugenia uniflora) e acerola (Malpighia glabra.). Rio de Janeiro, 1991. 73p. Dissertação (Mestrado) Instituto de Nutrição, Universidade Federal do Rio de Janeiro.

CHEFTEL, J.C.; CHEFTEL, H.; BESANÇON, P. Métodos de conservacíon. In: CHEFTEL, J.C.; CHEFTEL, H.; BESANÇON, P. (Ed.) Introduccion a la bioquímica y tecnología de los alimentos. Zaragoza: Acribia, 1983. v.2, cap.7, p.173-202.

GOMES, R.P. Fruticultura brasileira. 2.ed. São Paulo: Nobel, 1975. 446p.

GUIMARÃES, F.A.; HOLANDA, L.F.F. de; MAIA, G.A.; MOURA FÉ, J. de A. Estudos analíticos e físicos em polpa e semente de pitanga (Eugenia uniflora L.). Ciência e Tecnologia de Alimentos, v.2, p.208-215, 1982.

HARDENBURG, R.E.; WATADA, A.E.; WANG, C.Y. Almacenamiento comercial de frutas, legumbres y existencias de floresterias y viveiros. Costa Rica: IICA, 1988. 150p.

HARRIS, R.S. Effects of agricultural practices on foods of plant origin. In: HARRIS, R.S.; KARMAS, E. (Ed.) Nutritional evaluation of food processing. Connecticut: Avi Publishing, 1977. cap.6, p.33-57.
HOPKINS, F. Vitaminas. In: BRAVERMAN, J.B.S. (Ed.) Introduction a la bioquímica de los alimentos. Barcelona: Ediciones Omega, 1967. p.206-241.

KANESIRO, M.A.B.; PARO, R.M.; JERÔNIMO, E.M.; MARQUES, M.O.; TOSTES, D.R.D. Qualidade e vida útil de frutos de goiaba "paluma" submetidos a diferentes sistemas de embalagens. In: CONGRESSO BRASILEIRO DE CIÊNCIA E TECNOLOGIA DE ALIMENTOS, 15., Poços de Caldas, 1996. Resumos. Poços de Caldas: Tec Art Editora, 1996. $156 \mathrm{p}$.

LEDERMAN, I.E.; BEZERRA, J.E.F.; CALADO, G. A pitangueira em Pernambuco. Recife: Secretaria de Agricultura; IPA, 1992. $20 p$.

NAGY, S. Vitamin C contents of citrus fruits and their products: a review. Journal of Agricultural and Food Chemistry, v.28, p.8-18, 1980.

SAS INSTITUTE. SAS user's guide. Cary: Statistical Analysis System Institute, 1992.

SIGRIST, J.M.M. Distúrbios fisiológicos e pelo frio. In: INSTITUTO DE TECNOLOGIA DE ALIMENTO. Tecnologia pós-colheita de frutas tropicais. Campinas: ITAL, 1988. cap.4, p.43-50.

SILVA, J.J.M. Fatores que afetam o conteúdo de ácido ascórbico da acerola (Malpighia glabra L.). São Luiz: Equatorial, 1994. v.1, p.11-23. Caderno de agricultura.

STROHECKER, R.; HENNING, H.M. Vitamin assay tested methods. Weinheim: Verlag Chemie, 1965. 359p.

$\overline{\text { Recebido em } 01} .03 .00$ 